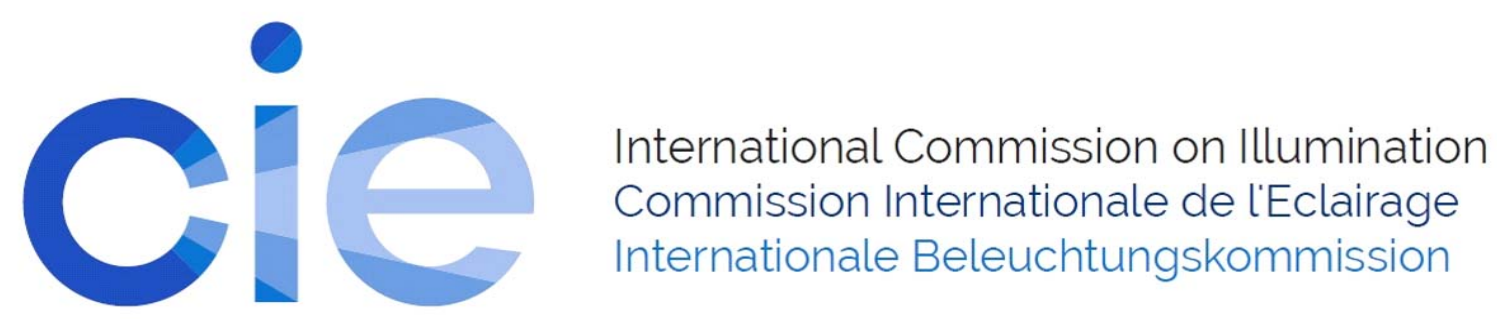

OP66

\title{
RESEARCH ON THE RANGE OF PLEASANT DARKNESS AND BRIGHTNESS IN RESTAURANTS: DISCUSSION ON AGE FACTOR
}

\section{Miki Kozaki et al.}

DOI 10.25039/x46.2019.OP66

from

CIE x046:2019

Proceedings

of the

29th CIE SESSION

Washington D.C., USA, June 14 - 22, 2019

(DOI 10.25039/x46.2019)

The paper has been presented at the 29th CIE Session, Washington D.C., USA, June 14-22, 2019. It has not been peer-reviewed by CIE.

(C) CIE 2019

All rights reserved. Unless otherwise specified, no part of this publication may be reproduced or utilized in any form or by any means, electronic or mechanical, including photocopying and microfilm, without permission in writing from CIE Central Bureau at the address below. Any mention of organizations or products does not imply endorsement by the CIE.

This paper is made available open access for individual use. However, in all other cases all rights are reserved unless explicit permission is sought from and given by the CIE.

CIE Central Bureau

Babenbergerstrasse 9

A-1010 Vienna

Austria

Tel.: +431714 3187

e-mail: ciecb@cie.co.at

www.cie.co.at 


\title{
RESEARCH ON THE RANGE OF PLEASANT DARKNESS AND BRIGHTNESS IN RESTAURANTS: DISCUSSION ON AGE FACTOR
}

\author{
Kozaki, M. ${ }^{1}$, Honjo, N. ${ }^{2}$, Hirate, K. ${ }^{3}$, Suzuki, N. ${ }^{4}$ \\ 1 Ochanomizu University, Tokyo, JAPAN, ${ }^{2}$ Ochanomizu University, Tokyo, JAPAN, \\ ${ }^{3}$ The University of Tokyo, Tokyo, JAPAN, ${ }^{4}$ ENDO Lighting corp., Tokyo, JAPAN.
}

kozaki.miki@ocha.ac.jp

DOI 10.25039/x46.2019.OP66

\begin{abstract}
This research aims to find the range of pleasantness, darkness and brightness for the elderly and compare with the results of related research targeting young adults. Three lighting patterns and four expected behaviours were selected as experimental variables, and adjustment method was used to derive each threshold value. Using luminance distribution taken at subject's view point, average luminance of the whole visual field was calculated, which was used to compare experiment outcomes. Following the analysis method used in related research, $50 \%$ response rate of logistic analysis was set as a threshold value. Unlike the experiment outcomes of young adults, the range of "pleasant darkness" was not observed for elderly. In general, pleasantness range of elderly was narrower than that of young adults, showing that elderly do not feel pleasant under dark or an environment that is too bright.
\end{abstract}

Keywords: age factor, pleasantness, brightness, darkness, restaurants

\section{Background information}

Many fundamental studies focusing on elderly have been conducted aiming to clarify the change in visual performances in the process of aging. It is generally known that age-related change affects visual performances, such as decrease of spectral transmittance of crystalline lens that reduces retinal illuminance or causes intraocular light scatter (CIE, 2017). However, those changes usually occur gradually, making it possible to adapt as it changes. Therefore, the following research question arose; decrease of visual performance may affect delicate tasks and may heighten mobility risks, but in what extent do they affect tasks that are less sophisticated, such as eating and drinking? Previous studies (Oe et al, 2014, Inoue et al, 2012) have suggested differences in lighting sensation of elderly and young adults, and that pleasantness varies among different behaviours.

Related research was conducted to determine a pleasant lighting environment in a restaurant setting targeting young adults. Restaurant was chosen as the experiment setting, as various range of brightness is used in restaurants. According to related research, lighting environment that can be defined as "pleasant darkness" and in some cases, "unpleasant brightness" exist for young adults (Kozaki et al, 2016).

This research aims to summarize related experiments on pleasantness, brightness and darkness range. In addition to previous experiments, an experiment of darkness and brightness range was conducted on elderly. Therefore, by comparing results, this research aims to discuss age factor related to pleasantness range of lighting environment when delicate visual tasks are not required.

\section{Apparatus and Method}

The method used in related research was applied to this research. Restaurant was chosen as the experimental setting, as brightness of the room ranges from darker lighting environment such as in bars, to brighter environment, for example family-friendly casual restaurants. Expected behaviour and lighting methods were selected as variables. Four behaviours, namely "eating", "drinking", "relaxing" and "chatting" were chosen to examine different visual direction and targets. In order to differentiate brightness distribution in the room, three lighting methods 
were selected; local lighting method using a spot light to lighten table, general lighting method using four down lights with wide lighting distribution, and indirect lighting method using cornice lighting around the three walls in vision.

Two experiments were conducted. As a basic experimental setting, a white interior room with no windows was used, although size of the rooms used for the two experiments was slightly different (Experiment 1: W4100mm $\times$ L3000mm $\times \mathrm{H} 2600 \mathrm{~mm}$, Experiment 2: W2900mm $\times$ L3000 $\mathrm{mm} \times \mathrm{H} 2600 \mathrm{~mm}$ ). Apparatus is shown in figure 1 and 2 . Mannequin and food replicas were placed according to the expected behaviour. Since the experimental room was different, lighting equipment was also different, but lighting simulation was carried prior to the experiment in order to select equipment that creates lighting environment that is close as possible to Experiment 1. Equipment used in the experiments are shown in table 1.

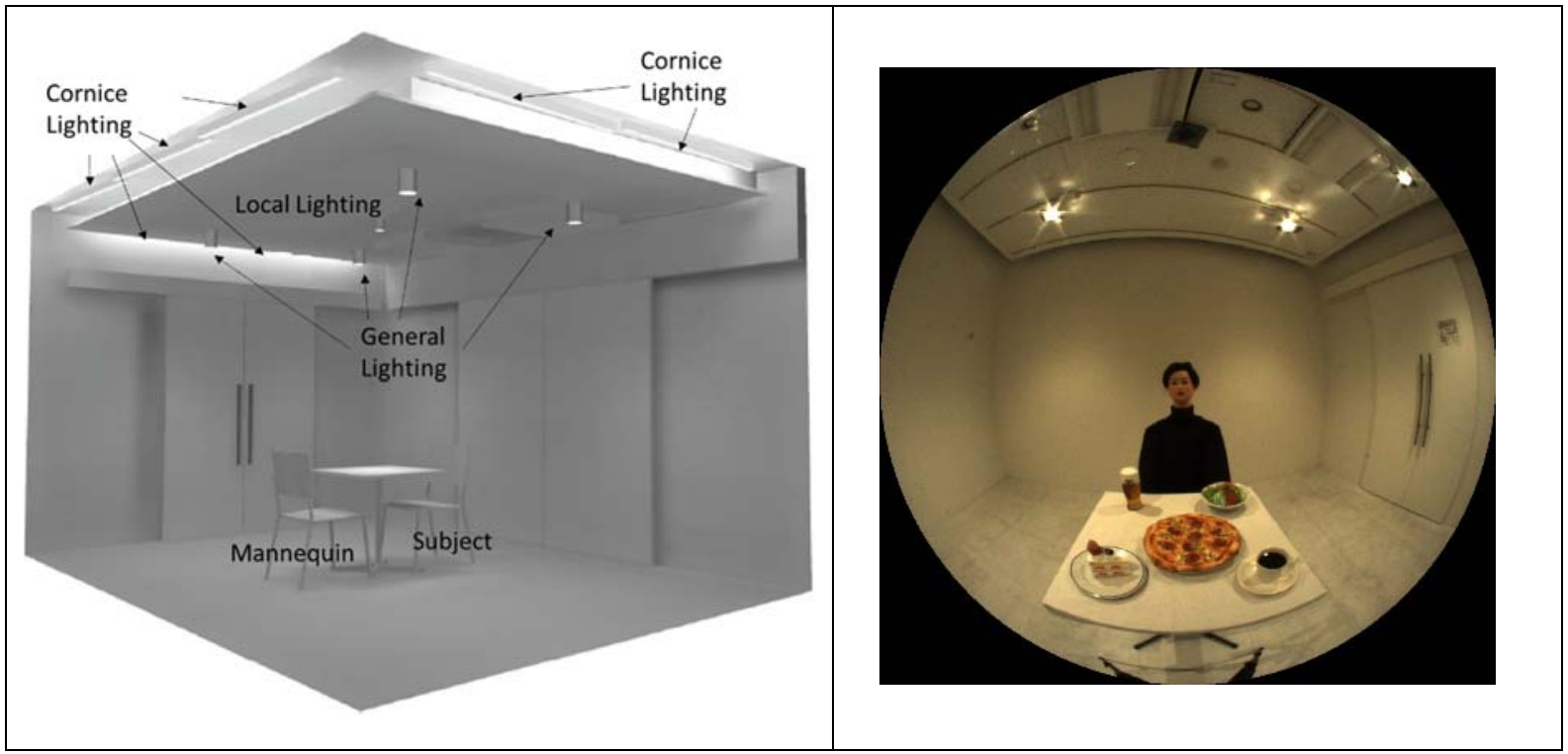

Figure 1 - Apparatus and lighting sample of general lighting in Experiment 1

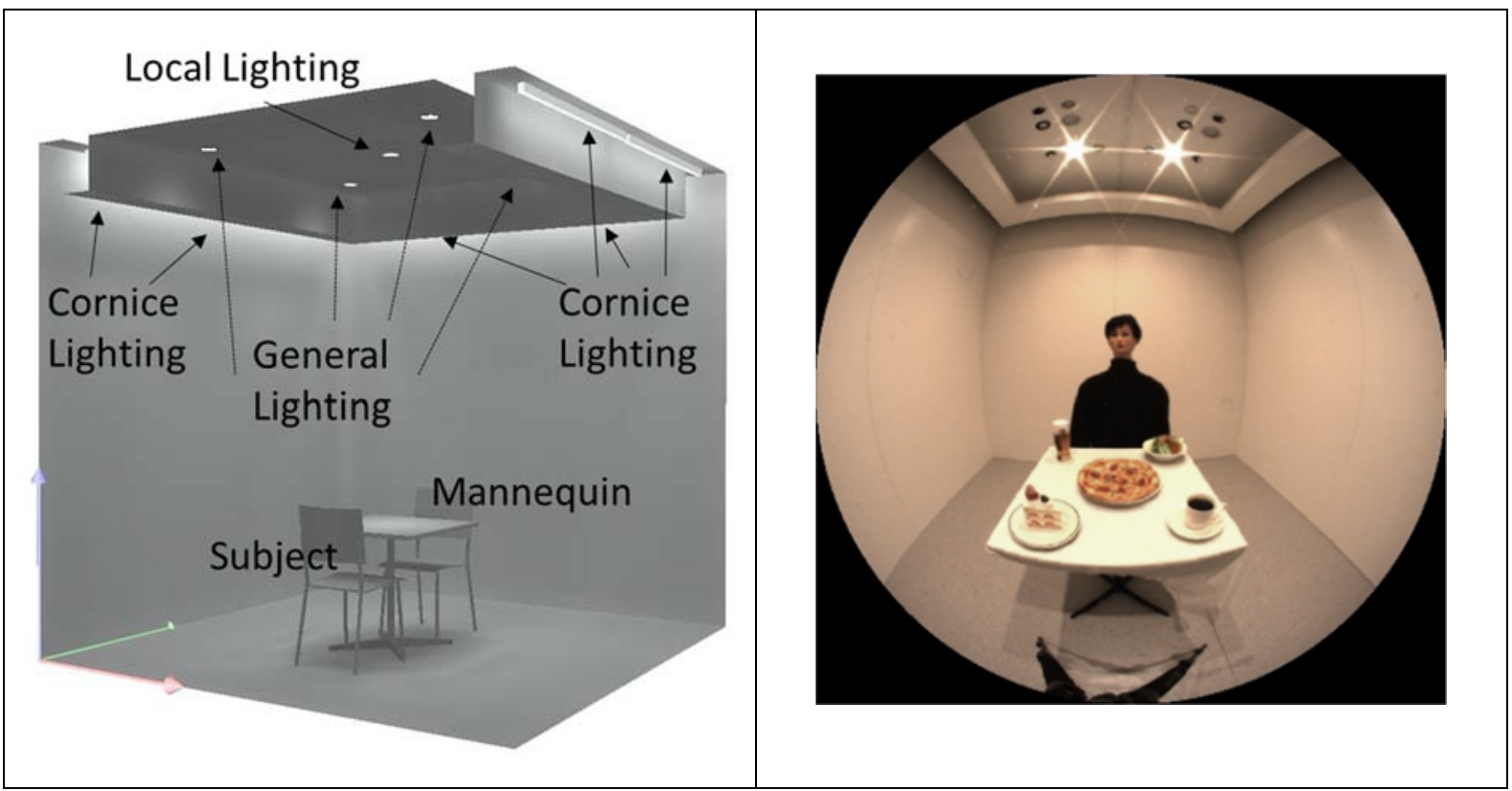

Figure 2 - Apparatus and lighting sample of general lighting in Experiment 2 
Table 1 - Lighting equipment

\begin{tabular}{|c|c|c|c|c|c|c|c|}
\hline Exp. & $\begin{array}{l}\text { Lighting } \\
\text { Method }\end{array}$ & $\begin{array}{l}\text { Used } \\
\text { Equipment }\end{array}$ & Number & $\begin{array}{l}\text { Colour } \\
\text { temperature }\end{array}$ & $\begin{array}{l}\text { Colour } \\
\text { Rendering }\end{array}$ & $\begin{array}{l}\text { Half-peak } \\
\text { divergence }\end{array}$ & $\begin{array}{l}\text { Adjust/ } \\
\text { Fix }\end{array}$ \\
\hline \multirow{4}{*}{1} & $\begin{array}{l}\text { Local } \\
\text { Lighting }\end{array}$ & Spot light & 1 & $3000 \mathrm{~K}$ & Ra85 & $16^{\circ}$ & Adjust \\
\hline & $\begin{array}{l}\text { General } \\
\text { Lighting }\end{array}$ & Down light & 4 & $3000 \mathrm{~K}$ & Ra85 & $60^{\circ}$ & Adjust \\
\hline & \multirow{2}{*}{$\begin{array}{l}\text { Indirect } \\
\text { Lighting }\end{array}$} & Spot light & 1 & $3000 \mathrm{~K}$ & Ra85 & $16^{\circ}$ & $\begin{array}{l}\text { Fix } \\
\text { (5\%out } \\
\text { put) }\end{array}$ \\
\hline & & $\begin{array}{l}\text { Cornice } \\
\text { light }\end{array}$ & 7 & $3000 \mathrm{~K}$ & Ra82 & $\begin{array}{l}\text { Wide } \\
\text { spread }\end{array}$ & Adjust \\
\hline \multirow{4}{*}{2} & $\begin{array}{l}\text { Local } \\
\text { Lighting }\end{array}$ & Spot light & 1 & $3000 \mathrm{~K}$ & Ra85 & $16^{\circ}$ & Adjust \\
\hline & $\begin{array}{l}\text { General } \\
\text { Lighting }\end{array}$ & Down light & 4 & $3000 \mathrm{~K}$ & Ra85 & $62^{\circ}$ & Adjust \\
\hline & \multirow{2}{*}{$\begin{array}{l}\text { Indirect } \\
\text { Lighting }\end{array}$} & Spot light & 1 & $3000 \mathrm{~K}$ & Ra85 & $16^{\circ}$ & $\begin{array}{l}\text { Fix } \\
\text { (5\%out } \\
\text { put) }\end{array}$ \\
\hline & & $\begin{array}{l}\text { Cornice } \\
\text { light }\end{array}$ & 6 & $3000 \mathrm{~K}$ & Ra82 & $\begin{array}{l}\text { Wide } \\
\text { spread }\end{array}$ & Adjust \\
\hline
\end{tabular}

Adjustment method was used to derive the threshold values by asking the subjects to adjust lighting power until psychological equivalence value. For the first experiment, subjects were asked to wait 15 minutes allowing to adapt, and then were asked to adjust to the psychological equivalence value instructed. Subjects were asked to adjust to the threshold between "dark" and "not dark", and "unpleasant" and "pleasant" in both upward and downward directions, resulting in 48 adjustments in total.

For the second experiment, four psychological equivalence values were asked; threshold values between "not bright" and "bright", "bright" and "too bright", "unpleasant" and "pleasant" (lower threshold value), and "pleasant" and "not pleasant" (upper threshold value). Subjects were asked to adjust in both upward and downward directions, resulting in 96 adjustments in total.

Related research was conducted targeting young adults in their 20 s and 30 s. Subjects in this research, respectively 22 subjects for Experiment 1 and 20 subjects for Experiment 2, were in their $60 \mathrm{~s}$ to $80 \mathrm{~s}$. In order to test the effect of cataract surgery, half of the subjects were chosen from the people who had history of cataract surgery, although no subject had significant eye disease at the time of the experiment (Table 2).

Table 2 - Number of subjects according to their attributes

\begin{tabular}{|l|l|l|l|}
\hline \multirow{2}{*}{ Experiment } & \multirow{2}{*}{ Gender } & History of cataract surgery \\
\cline { 3 - 4 } & & Positive & Negative \\
\hline \multirow{2}{*}{2} & Male & 5 & 6 \\
\cline { 2 - 4 } & Female & 5 & 6 \\
\hline \multirow{2}{*}{2} & Male & 5 & 5 \\
\cline { 2 - 4 } & Female & 5 & 5 \\
\hline
\end{tabular}

Lighting environment was measured in order to compare with previous research results. Lighting power was adjustable from $5 \%$ to $100 \%$ by $1 \%$, and the following measurements were taken in $5 \%$ range; illuminance values of the vertical plane of subject's face, vertical plane of mannequin's face, average of table top, and average of the wall. In addition, regression analysis was conducted to derive intermediate values. Luminance distribution was measured at the subject's eye level by CCD camera with fisheye lens in an equisolid angle. Average luminance of the whole visual field, table surface, the wall and mannequin's face was calculated using distribution value. These lighting environmental measurements were used to compare results among experiments. 


\section{Results}

\subsection{ANOVA}

Compared to young adults, it took more time for elderly in the process of adjusting. Two-way ANOVA was used to test validity of the experimental factors, testing main effects of the lighting method and behaviour, and its interactions using luminance values of the whole visual field. As a result, the only main effect of the lighting method in Experiments 1 and 2 was observed in darkness, brightness and pleasantness threshold value, and p-values for the following were all 0,0001 ; darkness and pleasantness in Experiment 1, lower and higher brightness and pleasantness in Experiment 2. On the other hand, main effect and interactions were statistically significant in ANOVA results for the experiments targeting young adults, implying sensitivity may decrease by age depending on the task.

In order to examine individual effects, ANOVA was used with subject's gender, age group and history of cataract surgery as factors. As a result, statistical difference was observed for darkness in Experiment 1, and either t-test or HSD test was conducted for each condition in order to examine further. As a result, statistical difference was observed for one condition by history of cataract surgery, namely drinking under local lighting, out of 12 conditions ( $p$-value: 0.0293). No effect was seen by gender and age group under other conditions.

On the other hand, statistical difference was detected by gender in lower brightness threshold value in Experiment 2. Therefore t-test and HSD test were conducted for a closer analysis under 24 conditions. As a result, statistical difference by gender was observed in one condition, namely chatting under general lighting in lower brightness threshold ( $p$-value 0,012), and statistical difference by age group in two conditions, namely eating under local lighting in higher pleasantness threshold value ( $p$-value 0,012 ) and chatting under indirect lighting in higher brightness threshold value ( $p$-value 0,040 ). No statistical difference was observed by the effect of cataract surgery.

Table 3 - ANOVA results on attributes of subjects

\begin{tabular}{|c|c|c|c|c|c|c|c|}
\hline \multirow[t]{2}{*}{ m } & \multirow{2}{*}{ Source of variation } & \multicolumn{3}{|c|}{ Darkness/ Brightness } & \multicolumn{3}{|c|}{ Pleasantness } \\
\hline & & DF & $\mathbf{F}$ & $p$ & DF & $\mathbf{F}$ & $\mathbf{p}$ \\
\hline \multirow[t]{3}{*}{$\rightarrow$} & Gender & 1 & 4,031 & $0,002^{* *}$ & 1 & 3,411 & 0,065 \\
\hline & Age group & 2 & 6,354 & $0,045^{*}$ & 2 & 0,155 & 0,856 \\
\hline & History of cataract surgery & 1 & 7,653 & $0,006^{* *}$ & 1 & 0,072 & 0,789 \\
\hline \multirow{3}{*}{ 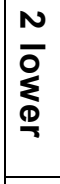 } & Gender & 1 & 5,319 & $0,022^{*}$ & 1 & 2,185 & 0,140 \\
\hline & Age group & 2 & 0,695 & 0,500 & 2 & 0,397 & 0,672 \\
\hline & History of cataract surgery & 1 & 1,023 & 0,312 & 1 & 0,108 & 0,743 \\
\hline \multirow{3}{*}{ 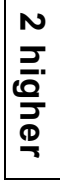 } & Gender & 1 & 2,882 & 0,090 & 1 & 0,575 & 0,449 \\
\hline & Age group & 2 & 1,257 & 0,285 & 2 & 0,387 & 0,680 \\
\hline & History of cataract surgery & 1 & 2,424 & 0,120 & 1 & 0,484 & 0,487 \\
\hline
\end{tabular}

NOTE: Asterisks indicate statistical significance

\subsection{Logistic Analysis Results}

Following the analytical method used in related study, threshold values were derived using logistic analysis. Logistic analysis is a method to plot positive response rate (y axis) by physical quantity ( $x$ axis), for example, average luminance and illuminance. Threshold value was set to $50 \%$ positive response rate. Quantity of $50 \%$ response rate was calculated and shown in figure 3 and 4 . Threshold values calculated using average luminance value were within the following range; darkness $6 \mathrm{~cd} \cdot \mathrm{m}^{-2}$ to $13 \mathrm{~cd} \cdot \mathrm{m}^{-2}$ and pleasantness $7 \mathrm{~cd} \cdot \mathrm{m}^{-2}$ to $16 \mathrm{~cd} \cdot \mathrm{m}^{-2}$ for Experiment 1 , lower brightness $17 \mathrm{~cd} \cdot \mathrm{m}^{-2}$ to $66 \mathrm{~cd} \cdot \mathrm{m}^{-2}$, higher brightness $30 \mathrm{~cd} \cdot \mathrm{m}^{-2}$ to $120 \mathrm{~cd} \cdot \mathrm{m}^{-2}$, lower 
pleasantness $17 \mathrm{~cd} \cdot \mathrm{m}^{-2}$ to $61 \mathrm{~cd} \cdot \mathrm{m}^{-2}$, higher pleasantness $35 \mathrm{~cd} \cdot \mathrm{m}^{-2}$ to $128 \mathrm{~cd} \cdot \mathrm{m}^{-2}$ for Experiment 2.

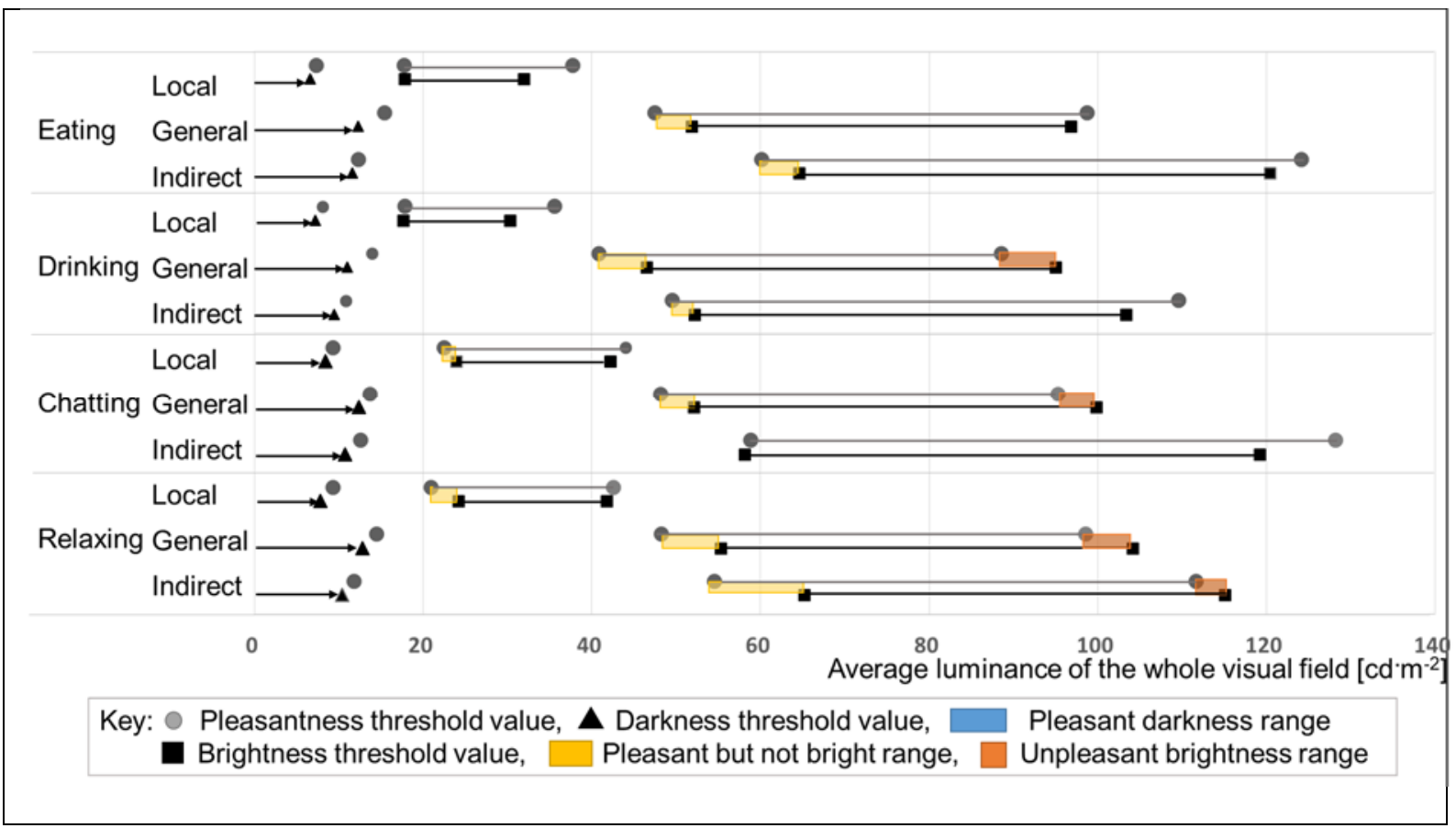

Figure 3 - Average luminance of the whole visual field for all experimental results

Result of average illuminance of table top was compared with Japan Industerial Standard (JIS Z9110) and Environmental Standards "AIJES-L0002-2016" (AIJES, 2016) published by Architectural Institute of Japan (Table 4). AIJES sets table top illuminance values apart from the average illuminance of the whole room. Darkness range was brighter than the standard for bar, and in most cases lower than the standard for restaurant. Half of the brightness range was darker than the standard for diner. It is stated in the standards that standard level may be set one level higher for people with visual difficulty, such as elderly (standard levels are set as 30 , $50,75,100,150,200,300,500,750 \ldots$ and so on). Experimental results show that depending on the lighting method, some elderly may be satisfied with the current brightness level, therefore simply increasing brightness may not solve the problem.

Table 4 - Illuminance standards values related to restaurants

\begin{tabular}{|l|l|l|l|}
\hline \multirow{2}{*}{ Standards } & Place and behaviour & \multicolumn{2}{l|}{ Average illuminance [lux] } \\
\cline { 3 - 4 } & & Room & Table top \\
\hline \multirow{3}{*}{ CIE } & Buffet & 300 & - \\
\cline { 2 - 4 } & Restaurant, dining room, function room & 200 & - \\
\hline \multirow{4}{*}{ AIS } & Restaurant & 200 & 500 \\
\cline { 2 - 4 } & Parlor & 100 & 300 \\
\cline { 2 - 4 } & Bar & 30 & - \\
\cline { 2 - 4 } & Diner & - & 300 \\
\cline { 2 - 4 } & Restaurant & - & 200 \\
\cline { 2 - 4 } & Parlor & - & 100 \\
\cline { 2 - 4 } & Bar & - & 30 \\
\hline
\end{tabular}




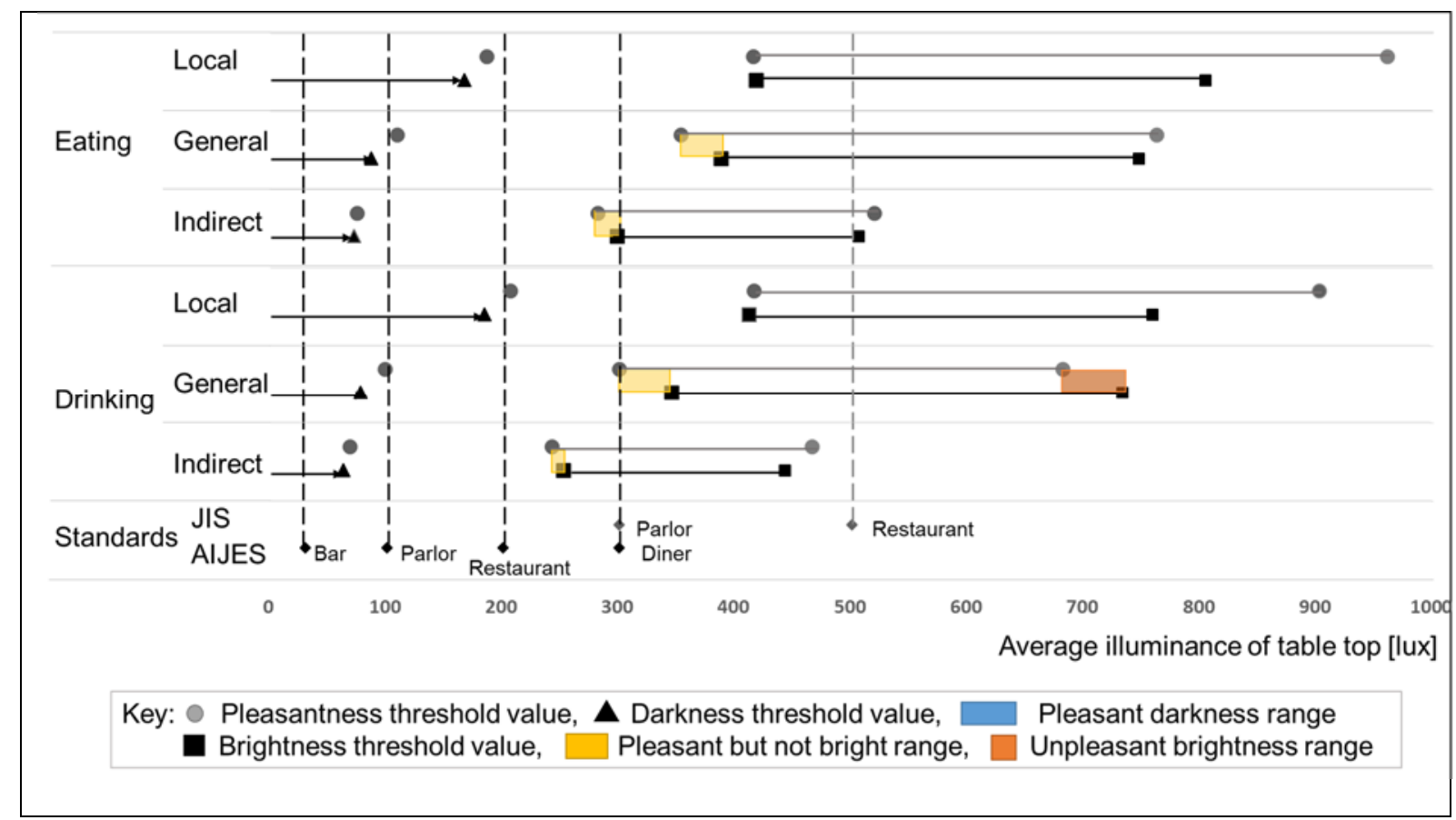

Figure 4 - Average illuminance of table top by experimental results and standards -Eating and Drinking-

\subsection{Values between not dark and bright}

Threshold value between dark and not dark was derived by Experiment 1, and threshold value between not bright and bright was derived by Experiment 2 (lower threshold). If darkness and brightness were in simple linear relationship (i.e. it is bright when not dark), threshold values would be the same. For comparison, t-test was conducted to see the statistical differences. As a result, statistical significance was present in all 12 conditions ( $p$-values all under 0,0001 ) for both brightness and pleasantness. Similar results were obtained by experiments of young adults. The adaptation level and evaluation method (it is possible that subjects are adjusting in relative terms by comparing conditions, not in absolute terms) might have an effect, but it is also possible that the darkness and brightness may not simply have a linear relationship.

\section{Discussion on Age Factor}

Experimental results were compared with related research (Kozaki et al, 2017) in order to discuss age factor. Compared with young adults, elderly had narrower range of pleasantness and brightness (Figure 5). Under local lighting, pleasantness range of elderly was brighter than young adults, and under general and indirect lighting, pleasantness range of elderly was narrower than young adults. This corresponds with the known fact that elderly has lower visual performance (having difficulty seeing under dark conditions) and lens opacification (suffering from glare under bright conditions). In general, distribution curve of elderly was wider, indicating greater individual differences for elderly.

Unlike the results with young adults, "pleasantness" does not exist in darkness range, as darkness threshold value was darker than the pleasantness threshold value. In some cases, range that is pleasant but not bright and unpleasant brightness range were observed. While several possible reasons can be raised, most possible reason may be the image of the word "darkness." The concept of "brightness as a symbol wealth" was broadly acknowledged during the high economic growth period. During that period, standard values increased in accordance with the development of lighting technology, which led to a wide use of fluorescent lamps in Japan. For elderly, the word "darkness" already conveys the negative image, which is not associated with pleasantness. Unlike elderly, many young adults do not have a negative image towards "darkness", thus recognizing the "pleasant darkness" range. 


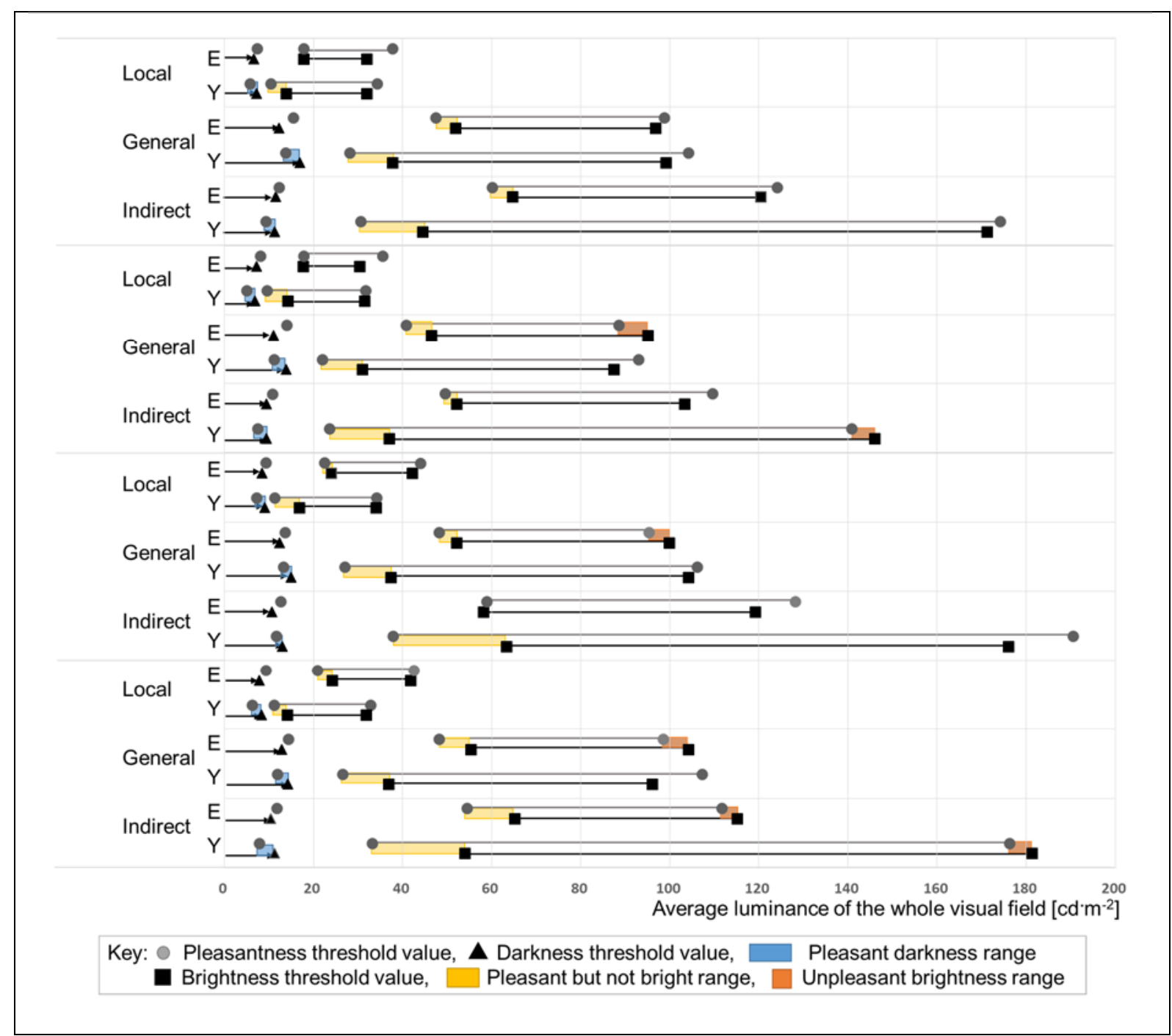

Figure 5 - Age group comparison (young adults and elderly) of average luminance of the whole visual field (all experimental results)

In order to consider the age difference, t-test was conducted under each condition using average luminance of the whole visual field (Table 5). Comparing darkness or brightness to pleasantness, greater statistical difference is observed in pleasantness, indicating that required lighting level may not differ between the age groups, although whether they feel pleasant or not may differ.

Lighting method may have an effect on the range as well. For higher brightness under general lighting, no statistical difference is observed, but under indirect lighting, differences are observed for all four behaviours. 
Table 5 - $t$-test results of age factor ( $p$-values)

\begin{tabular}{|c|c|c|c|c|c|c|c|c|c|}
\hline \multirow[t]{2}{*}{$\begin{array}{l}\text { m } \\
\underline{x} \\
0\end{array}$} & \multirow{2}{*}{$\begin{array}{l}\text { Lighting } \\
\text { method }\end{array}$} & \multicolumn{4}{|c|}{ Darkness/ Brightness } & \multicolumn{4}{|c|}{ Pleasantness } \\
\hline & & Eat & rink & hat & Relax & at & rink & hat & Relax \\
\hline \multirow[t]{3}{*}{$\rightarrow$} & Local & 0,884 & 0,002 & 0,529 & 0,708 & 0,040 & 0,0001 & 0,010 & 0,0003 \\
\hline & General & 0,015 & 0,058 & 240 & 0,262 & 0,568 & 0,040 & 0,945 & 0,048 \\
\hline & $\ln$ & 0 & 0,457 & 2 & - & 2 & 7 & 6 & 0,001 \\
\hline \multirow[t]{3}{*}{$\frac{N}{0}$} & Local & 0,001 & 0,010 & 0,0001 & 0,0001 & 0,0001 & 0,0001 & 0,0001 & 0,0001 \\
\hline & General & 0,0007 & 0,0001 & 0,0001 & 0,0001 & 0,0001 & 0,0001 & 0,0001 & 0,0001 \\
\hline & Indirect & 0,011 & 0 & 0 & 0 & 0,00 & 1 & 0 & 0,001 \\
\hline \multirow{3}{*}{ 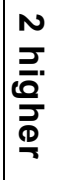 } & Local & & & & & & & 0003 & 0,0002 \\
\hline & General & 0,758 & 0,100 & ו ו & 0,209 & 0,291 & 0,631 & 0,123 & 0,389 \\
\hline & Indirect & 0,0001 & 0,0001 & 0,0001 & 0,0001 & 0,0001 & 0,003 & 0,0001 & 0,0001 \\
\hline
\end{tabular}

NOTE: Grey shaded cells indicate no statistical significance

\section{Conclusion}

This research aimed to verify the subjective range of darkness, brightness and pleasantness, and compare with the result of the related research on young adults to discuss the age factor. Corresponding with the hypothesis, pleasantness range of elderly was narrower than the young adults. Darkness and brightness threshold values were similar between the age groups compared to the pleasantness threshold value, which suggests that although necessary lighting level may not differ between the age group, pleasantness of the lighting environment may differ. In addition, threshold values of "not dark" was not equivalent to that of "bright", indicating the word nuance may have an influence over subjective range.

\section{References}

AIJ 2016. AIJES-L0002-2016. Architectural Institute of Japan. Standards for Lighting Environment. Tokyo: AlJ.

CIE 2001. CIE S 008/E:2001. Lighting of work places -Part 1 Indoor. CIE.

CIE 2017. CIE 227:2017. Lighting for Older People and People with Visual Impairment in Buildings (DOI: 10.25039/TR.227.2017).

Inoue Y. Ueno A. Oe Y. (2012.5) Age Difference in Comfortable Lighting: Part 2 Suitable Condition of Illuminance and Light Color for Act in Daily Life. Reports of Kinki branch research. Environment (52): 81-84

Kozaki, M., Yang, L. and Hirate, K. (2017.10) Research on the Range of Pleasant Darkness and Brightness in Restaurants, CIE, Proceedings of the Conference "Smarter Lighting for Better Life" CIE Midterm Meeting 2017, 1018-1026

Oe Y. Inoue Y. (2014.5) Age Difference in Comfortable Lighting: The consideration of the experiment in actual spaces about the adjustment speed of illuminance and correlated color temperature. Reports of Kinki branch research. Environment (54): 49-52 